Cole, Steven J .; Moore, Robert J .. 2008 Distributed hydrological modelling using weather radar in gauged and ungauged basins. In: International Symposium on Weather Radar and Hydrology, Grenoble, 10-12 March 2008.

This version available at http://nora.nerc.ac.uk/2640/

NERC has developed NORA to enable users to access research outputs wholly or partially funded by NERC. Copyright and other rights for material on this site are retained by the authors and/or other rights owners. Users should read the terms and conditions of use of this material at http://nora.nerc.ac.uk/policies.html\#access 


\title{
Distributed hydrological modelling using weather radar in gauged and ungauged basins
}

\author{
Steven J. Cole, Robert J. Moore \\ Centre for Ecology and Hydrology, Wallingford (UK)
}

\section{Introduction}

Distributed hydrological modelling using space-time estimates of rainfall from weather radar provides a natural approach to area-wide flood forecasting and warning at any location, whether gauged or ungauged. However, radar estimates of rainfall may lack consistent, quantitative accuracy. Also, the formulation of hydrological models in distributed form may be problematic due to process complexity and scaling issues. Here, the aim is to first explore new ways of improving radar rainfall accuracy through combination with raingauge network data via integrated multiquadric methods. The gridded rainfall estimators are assessed in relation to an extreme storm event.

Secondly, simple forms of physical-conceptual distributed

hydrological model are considered, capable of exploiting spatial datasets on topography and, where necessary, landcover, soil and geology properties. The simplest Grid-toGrid model uses only digital terrain data to delineate flow pathways and to control runoff production, the latter by invoking a probability-distributed relation linking terrain slope to soil absorption capacity. Model performance is assessed in gauged and ungauged contexts over nested river basins in northwest England, employing a lumped model as a reference.

2 Gridded estimates of rainfall using weather radar and raingauge data

The classical problem of surface fitting is to construct a surface which passes exactly through $\mathrm{N}$ data values, $\left(\mathrm{z}_{1}, \mathrm{~K}, \mathrm{z}_{\mathrm{N}}\right)=\underline{\mathrm{z}}^{\mathrm{T}} \quad$ specified at $\mathrm{N}$ locations, $\left\{\underline{x}_{i}=\left(x_{i}, y_{i}\right), i=1, K, N\right\}$. For application to rainfall

Corresponding author: Steven Cole

scole@ceh.ac.uk estimation on a grid, these data values may be measurements from a raingauge network or radar gauge-adjustment factors (defined as some ratio of gauge to coincident radar value and used to adjust radar data), and both assigned to the point gauge location.

An extended form of multiquadric surface is used based on the weighted sum of $\mathrm{N}$ distance functions, $\mathrm{g}(\cdot)$, centred on each of the $\mathrm{N}$ data locations; that is

$$
\mathrm{s}(\underline{\mathrm{x}})=\underline{\mathrm{a}}^{\mathrm{T}} \underline{\mathrm{v}}+\mathrm{a}_{0}
$$

where $\underline{\mathrm{a}}^{\mathrm{T}}=\left(\mathrm{a}_{1}, \mathrm{~K}, \mathrm{a}_{\mathrm{N}}\right)$ is a surface parameter vector, $\underline{\mathrm{v}}^{\mathrm{T}}=\left(\mathrm{g}\left(\underline{x}^{-} \underline{\mathrm{x}}_{1}\right), \mathrm{K}, \mathrm{g}\left(\underline{\mathrm{x}}^{-} \underline{\mathrm{x}}_{\mathrm{N}}\right.\right.$ is the distance function )

vector and $g(\underline{x})=\sqrt{\left(x^{2}+y^{2}\right)}$ is the Euclidean distance function. The inclusion of the constant $a_{0}$ avoids biased areal estimation associated with the case $a_{0}=0$.

The $\mathrm{N}+1$ multiquadric surface parameters $\left\{\mathrm{a}_{\mathrm{j}}, \mathrm{j}=0, \mathbf{K}, \mathrm{N}\right\}$ are determined by the following conditions. Firstly requiring $\left\{s\left(\underline{x}_{i}\right)=z_{i}, i=1, K, N\right\}$ gives $\mathrm{N}$ equations

$$
\mathrm{G} \underline{\mathrm{a}}+\mathrm{a}_{0} \underline{1}=\underline{\mathrm{z}}
$$

where $G$ is an $N$ by $N$ matrix and $G_{i j}=g\left(\underline{x}_{i}-\underline{x}_{j}\right)$. The remaining constraint applied is the flatness at large distance constraint

$$
\underline{\mathrm{a}}^{\mathrm{T}} \underline{1}=0 \text {. }
$$

Following Balascio (2001), it can be shown that the areal average, $\mathrm{S}$, of a multiquadric surface, $\mathrm{s}(\underline{\mathrm{x}})$, over a given region $\mathrm{R}$ (e.g. a grid-square or catchment), is equivalent to 
applying a set of $\mathrm{N}$ linear weights, $\left(\mathrm{w}_{1}, \mathrm{~K}, \mathrm{w}_{\mathrm{N}}\right)=\underline{\mathrm{w}}^{\mathrm{T}}$, to the $\mathrm{N}$ data values, $\underline{\mathrm{z}}$; that is

$$
S=\frac{1}{A} \iint_{R} s(\underline{x}) d x d y=\underline{w}^{T} \underline{z} \text { where } A=\iint_{R} d x d y .
$$

Applying constraints (2) and (3) gives

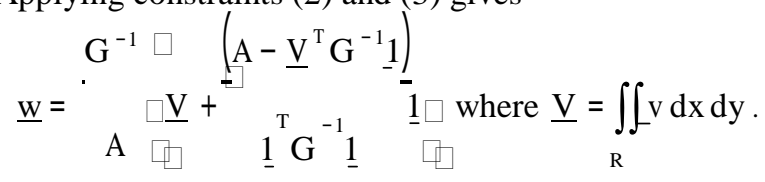

Importantly $\underline{\mathrm{w}}$ is a constant vector and only depends on the spatial location of the data points, $\underline{x}_{i}$. Therefore these weights can be applied to the grid-square or catchment regardless of the actual value of $\underline{z}$ and only need to be recalculated if the set of data locations (i.e. the raingauge network) changes. This approach is referred to here as the integrated multiquadric method and is used to obtain gridded rainfall estimates from radar and/or raingauge data.

Two radar products available in real-time from the Met Office, are used: raw radar and Nimrod data. The Nimrod processing includes physical-based corrections and a mean bias gauge-adjustment scheme (a modified version of the NEXRAD scheme applied to hourly raingauge network data).

Here a more dynamic approach is used to combine information from the raingauge network with either raw or Nimrod radar data. Integrated multiquadric estimation is used to generate gridded spatially-varying gauge-adjustment fields at 15 minute time intervals. The scheme used here is referred to as dynamic gauge-adjustment of radar (Wood et al., 2000). For comparison, a $1 \mathrm{~km}$ raingauge-only rainfall estimator is also created using the integrated multiquadric approach.

Examples of the radar, gauge-adjusted radar and raingaugeonly gridded rainfall estimators are presented for the nested River Kent case study catchments in Fig. 1. The period shown is during a significant orographic event which affected the English Lake District (Moore et al., 2006). The $2 \mathrm{~km}$ Nimrod radar data shows a general underestimation relative to the raingauge data to the north of the domain
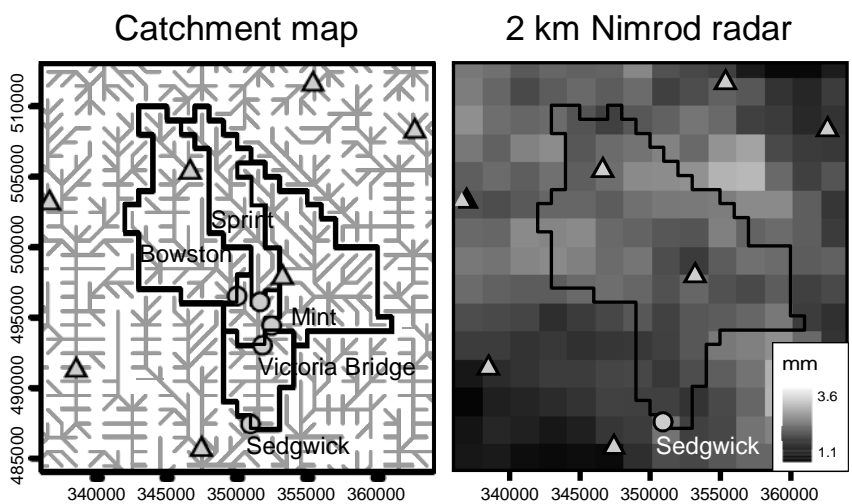

○ Gauging station whilst there is good agreement in the south-west corner. The third column indicates how the spatially varying gaugeadjustment scheme barely changes the south-west corner of the radar data but applies a significant increase to the north.

These example results provide some evidence for the need to apply spatially-varying gauge-adjustment schemes that dynamically change with time. However, the main concern here is to assess their utility from a hydrological modelling

perspective.

\section{The distributed hydrological model}

A grid-based runoff production and routing model - called the Grid-to-Grid model or G2G model (Bell et al., 2007; Moore et al., 2007) - is used as the distributed hydrological model in the assessment of the different rainfall estimators. The model has been developed on a grid for area-wide flood forecasting so it can be used to forecast river flows at both gauged and ungauged sites. It is designed to be used with gridded rainfall estimates. A simple physical-conceptual formulation allows the model to be configured directly using spatial datasets on terrain and, where necessary, soil, geology and land-cover properties. Here, the simplest form of the G2G model is used that requires only digital terrain data and is configured on a $1 \mathrm{~km}$ grid. Terrain slope is used to infer the capacity of the land to absorb water and to infer flow paths whose lengths control water translation through a catchment. This spatial dataset support leaves only a small number of regional model parameters to manually calibrate.

A schematic of the Grid-to-Grid model is given in Fig. 2. The model can be split into two distinct parts: the runoff production scheme which acts in each grid-square to generate fast ("surface") and slow ("subsurface") runoffs; and the grid-to-grid flow routing scheme which routes these runoffs across the model domain.

\section{Hydrological model assessment of different rainfall} estimators at gauged locations

In this section the objective is to assess the utility of the different rainfall estimators from a hydrological modelling
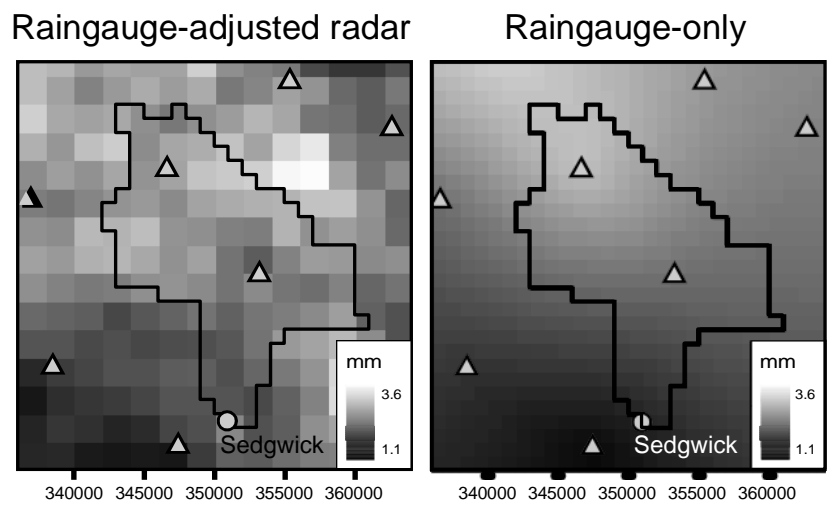

$1 \mathrm{~km}$ boundaries

Fig. 1.15 minute rainfall accumulations derived using different estimators for the orographic storm affecting the River Kent on 3 February 2004. The first column shows the hydrometric network along with hand-corrected $1 \mathrm{~km}$ resolution flow directions and catchment boundaries. 


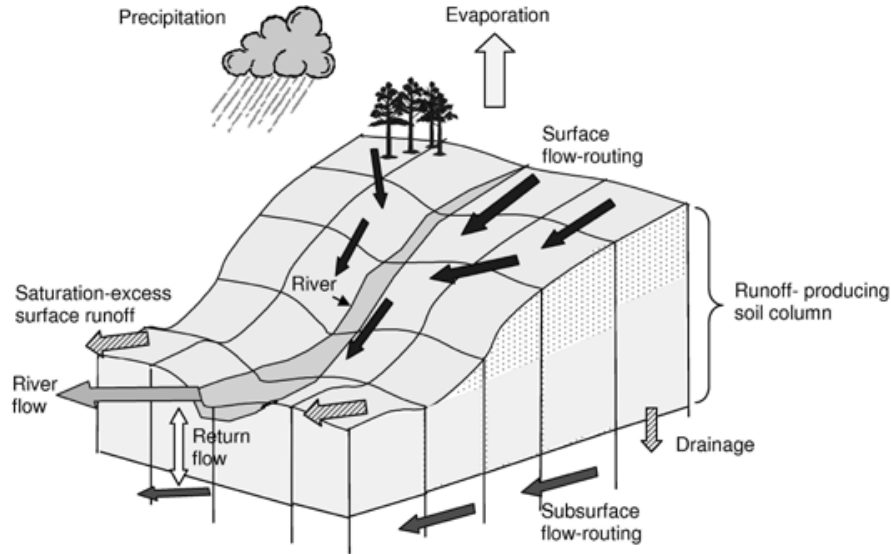

Fig. 2. The Grid-to-Grid distributed hydrological model

perspective and we shall restrict our attention to the downstream gauging location (Sedgwick, see Fig. 1) used to calibrate the distributed G2G model. Results from a lumped rainfall-runoff model, the PDM (Probability Distributed Model, Moore (2007)) serve as a useful benchmark.

Model hydrographs during an extreme orographic event (not used for model calibration) are compared to observed flows in Fig. 3 using five different rainfall estimators and a model time-step of 15 minutes. Visual inspection of the simulated hydrographs is very informative and highlights the typical modelling difficulties encountered when using unadjusted radar data. For example, the simulation results obtained using the $2 \mathrm{~km}$ raw radar estimator significantly overestimate the observed flow peaks during days 2 and 3 whilst significantly under-estimating the observed peak at the start of day 5. No set of model parameters (G2G or PDM) can resolve this. The time-scales of these periods of over-/underestimation can be less than a day and implies that a gaugeadjusted radar rainfall estimator needs to be able to respond on a sub-daily (and possibly sub-hourly) time-scale. Here, the dynamic and spatially varying gauge-adjustment scheme, applied at 15 minute intervals, greatly improves the flow simulations during these periods of over-/under-estimation (see middle column, Fig. 3). These results highlight that a gauge-adjustment scheme is currently needed for radar data products, of the kind available in the UK, to have any utility in a hydrological modelling context.

5 Distributed hydrological modelling at ungauged locations using weather radar

Next, we assess the potential of using gauge-adjusted radar data with a distributed model for predicting flows at ungauged locations. This situation has been replicated by ignoring the existence of the sub-catchment gauging stations during the calibration of the Grid-to-Grid model. As a benchmark, PDM results from models calibrated using the observations at each gauging location are also presented.

A real appreciation of the G2G model performance in an ungauged capacity is gained from visualising the simulated hydrographs at the interior locations: see Fig. 4. These immediately reveal two key features of the distributed G2G model performance that are replicated over all events studied. Firstly, the generally good performance at the downstream gauging station used for model calibration (Sedgwick, drainage area $212 \mathrm{~km}^{2}$ ) is replicated consistently throughout the catchment at the interior 'ungauged' locations (drainage areas 35 to $185 \mathrm{~km}^{2}$ ) and over a range of flows (at least up to the maximum validity of the rating curves). Secondly, the G2G model performances at the 'ungauged' locations compare reasonably well with those of the site-specific PDM models.

An understanding of how the G2G model works in a spatial sense is presented in Fig. 5. The right-hand column shows the $1 \mathrm{~km}$ grid-square soil capacity, $\mathrm{S}_{\max }$, used in the runoff production component of the model. These are derived using topographic datasets and, for the River Kent, gives smaller capacities in the headwaters. Rainfall accumulations over a
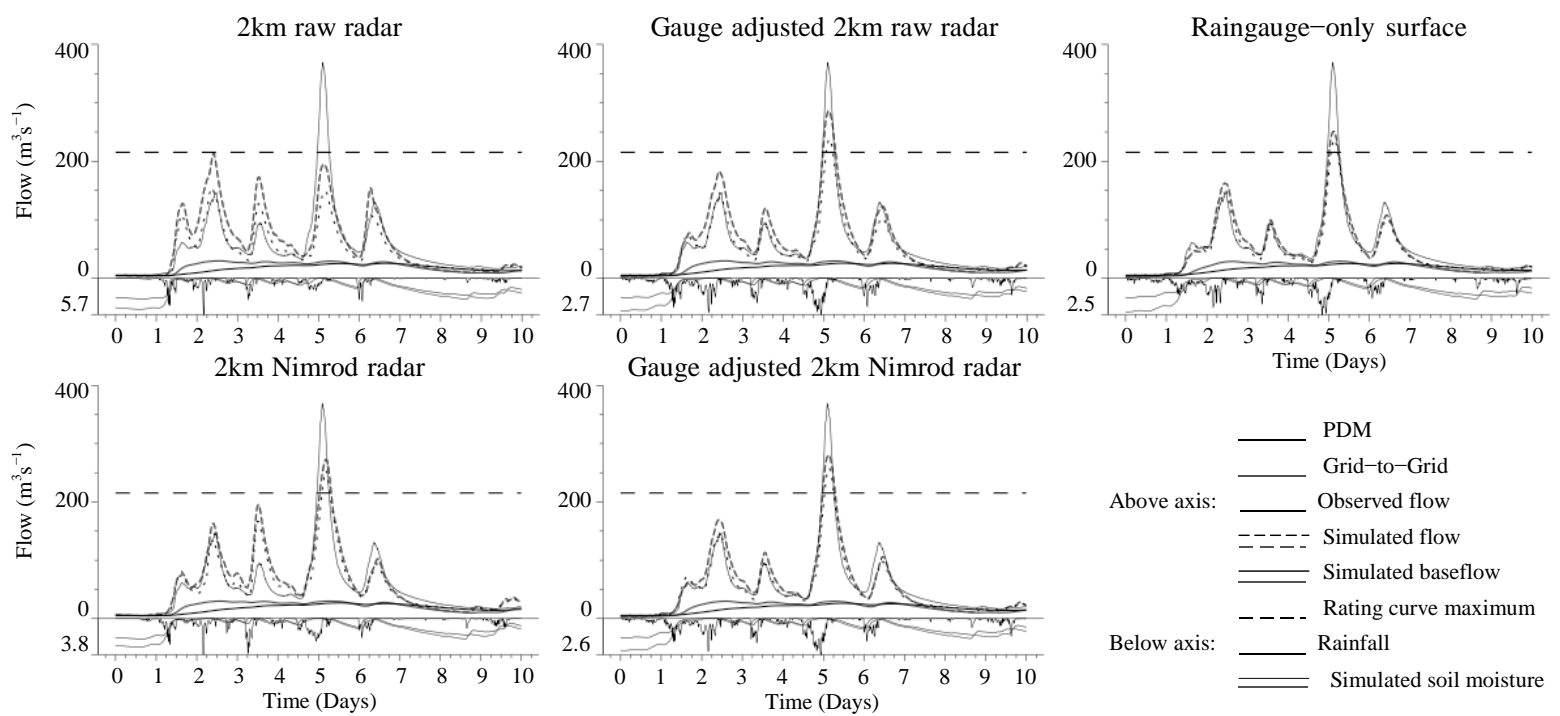

Fig. 3. Model simulated river flows for the River Kent at Sedgwick using the five different rainfall estimators (for the evaluation period 29 January to 8 February 2004). The figure below the axis is the maximum 15 min catchment average rainfall. 

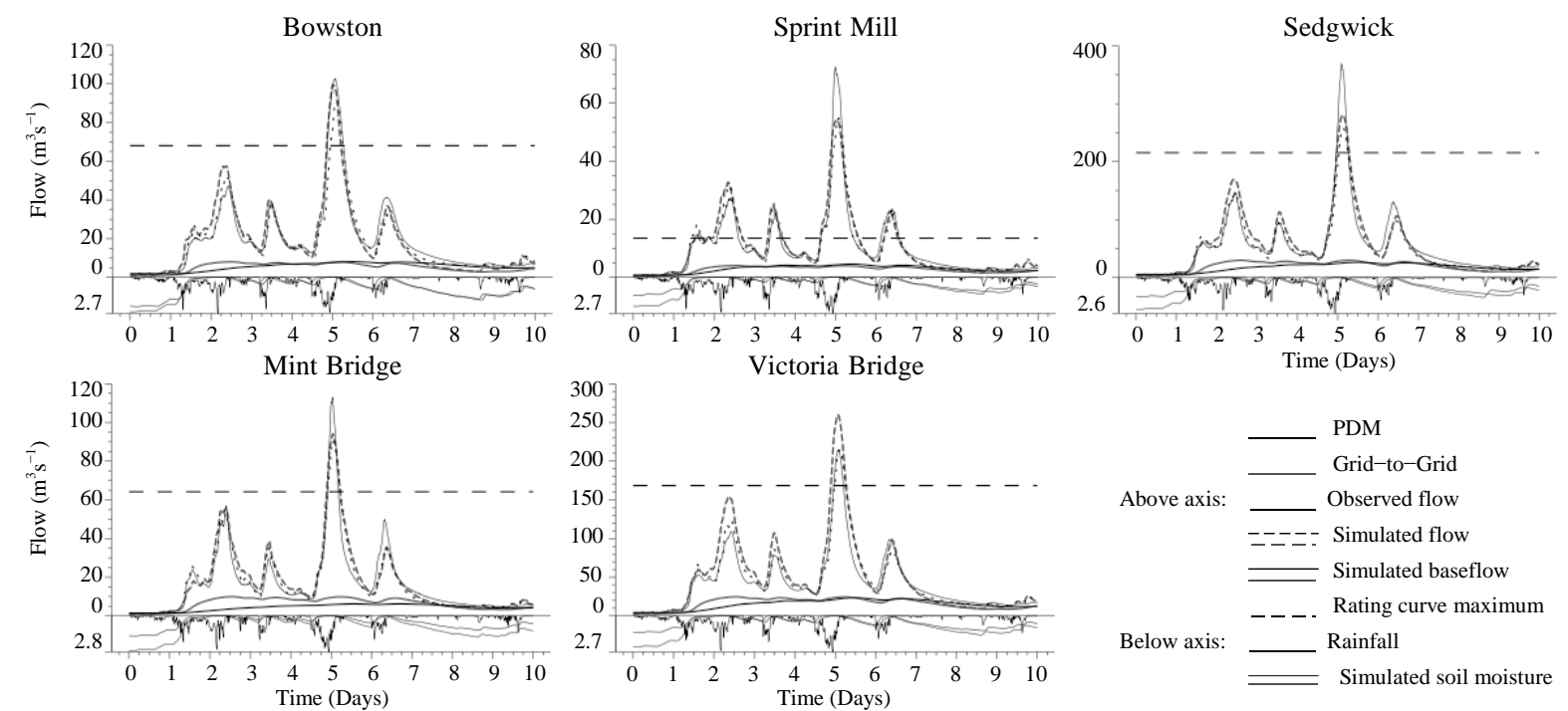

Fig. 4. Model simulated river flows for the River Kent gauging locations using gauge-adjusted 2 km Nimrod radar data (for the evaluation 29 January to 8 February 2004). The figure below the axis is the maximum 15 min catchment average rainfall.
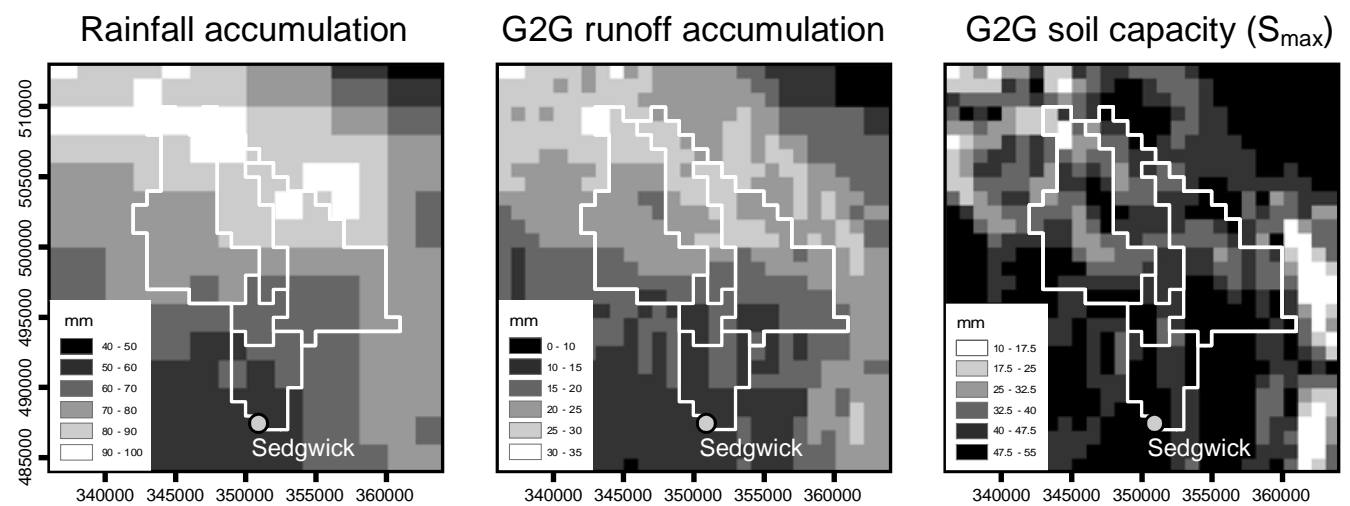

Fig. 5. Maps highlighting the distributed runoff component of the G2G model for the River Kent over the 24-hour evaluation period ending 12:00 2 February 2004.

24-hour period during the evaluation event are mapped in the left-hand column. The resulting G2G surface-runoff accumulations are presented in the middle column: this map illustrates how the runoffs are influenced by the spatial distributions of both the rainfall and the soil capacity.

\section{Conclusions}

The hydrological modelling case studies clearly show that, for the radar products currently available in the UK to have any appreciable utility for flood modelling, a frequent and spatially-varying gauge-adjustment scheme is needed. The integrated multiquadric method developed here to form 'gauge-adjusted radar' rainfall estimates is simple to apply and shows real benefits for hydrological modelling.

Encouraging results obtained with the Grid-to-Grid model support the view that grid-based physical-conceptual runoffproduction and routing models have an important future role to play in area-wide forecasting and flood warning for ungauged locations. Improved radar-raingauge rainfall estimators will play a key part in these developments at catchment, regional and national scales.

\section{References}

Balascio C.C., 2001: Multiquadric equations and optimal areal rainfall estimation. J. Hydrol. Engng., 6(6), 498-505.

Bell V.A., A.L. Kay, R.G. Jones, and R.J. Moore, 2007: Development of a high resolution grid-based river flow model for use with regional climate model output. Hydrol. Earth Syst. Sci., 11(1), 532-549.

Moore R.J., 2007: The PDM rainfall-runoff model. Hydrol. Earth Syst. Sci., 11(1), 483-499.

Moore R.J., V.A. Bell, S.J. Cole, and D.A. Jones, 2006: Spatiotemporal rainfall datasets and their use in evaluating the extreme event performance of hydrological models. R\&D Project Report FD2208/PR, Joint Defra/EA Flood and Coastal Erosion Risk Management, Research Contractor: CEH Wallingford, Defra.

Moore R.J., V.A. Bell, S.J. Cole, and D.A. Jones, 2007: Rainfallrunoff and other modelling for ungauged/low-benefit locations. Science Report - SC030227/SR1, Research Contractor: CEH Wallingford, Environment Agency.

Wood S.J., D.A. Jones, and R.J. Moore, 2000: Static and dynamic calibration of radar data for hydrological use. Hydrol. Earth Syst. Sci., 4(4), 545-554. 